\section{The Halton District School Board Focus: Assessing for Learning}

\section{Susan Orchard}

T leachers have been asked to make significant changes in their classroom assessment practices over the last few years. Prior to secondary school reform, most teachers' past experiences and learning focused on norm referenced evaluation that was communicated by a percentage grade on the report card. Throughout the course, students' efforts and achievement in relationship to paper pencil tasks were recorded, averaged and calculated to determine the final grade.

New education policies require classroom teachers to focus on assessment to help students learn. Learning opportunities and assessment tasks focus on key knowledge and skills (e.g., knowledge/understanding, thinking/inquiry, communication, application) that students practice over time before they are asked to demonstrate what they know and can do. Evidence of students' learning is gathered and judged against clear criteria related to curriculum expectations. Separate feedback on learning skills is provided on the right side of the report card while students' final percentage grades and comments related to strengths, areas for improvement and suggestions for improvement are on the left side.

Halton District School Board recognized the need for a focused, connected and sustainable professional learning plan to change classroom assessment practices across the system. The realities of a limited number of program staff, a reduced amount of time for learning and the huge shift in what is now considered effective classroom practices have created numerous implementation challenges.

Each year, plans for staff learning in Halton have taken three questions into consideration:

i) what learning needs to be addressed? ii) who needs the learning opportunities?

iii) how will the learning take place?

The first step in developing system plans continually requires us to determine what learning needs to be addressed. Recognizing past practices, present practices and the desired future state of classroom practices is taken into consideration. Each spring, teacher feedback is gathered on classroom practices related to the four key components of the assessment policy (curriculum expectations, achievement chart, $70 \% / 30 \%$ split for the final grade and learning skills). Teachers use profiles that identify and describe the expected classroom practices at various stages of implementation (awareness, preparation, practice, routine). This helps them determine the degree to which the assessment practices have become part of their daily routine. The self-assessment tool reinforces the concept that "implementation is a process and not an event" and assists them in planning future professional growth.

For each school year, new staff learning expectations are set based on what is appropriate to

\begin{tabular}{|l|l|l|l|l|l|}
\hline Policy Component & $1998-1999$ & $1999-2000$ & $2000-2001$ & 2001-2002 & 2002-2003 \\
\hline Curriculum Expectations & & & & & \\
\hline Achievement Chart & & & & & \\
\hline $70 \% / 30 \%$ & & & & & \\
\hline Learning Skills & & & & & \\
\hline
\end{tabular}

Key:

\begin{tabular}{|l|l|}
\hline Aspects of the policy not incorporated into the system staff learning plan & \\
\hline Aspects of the policy incorporated into the system staff learning plan & \\
\hline Aspects of the policy that were a focus in the system staff learning plan & \\
\hline
\end{tabular}


the stage of implementation for the system and what is manageable for teachers. The profiles are then updated to reflect the focus of the learning for the year. Data gathered from the teacher profiles and school administrators is used to make decisions related to plan.
Each stage of implementation required different learning opportunities. Staff learning delivery models were developed to address the needs of educators at different stages. When working with educators at the awareness stage, it was important to develop

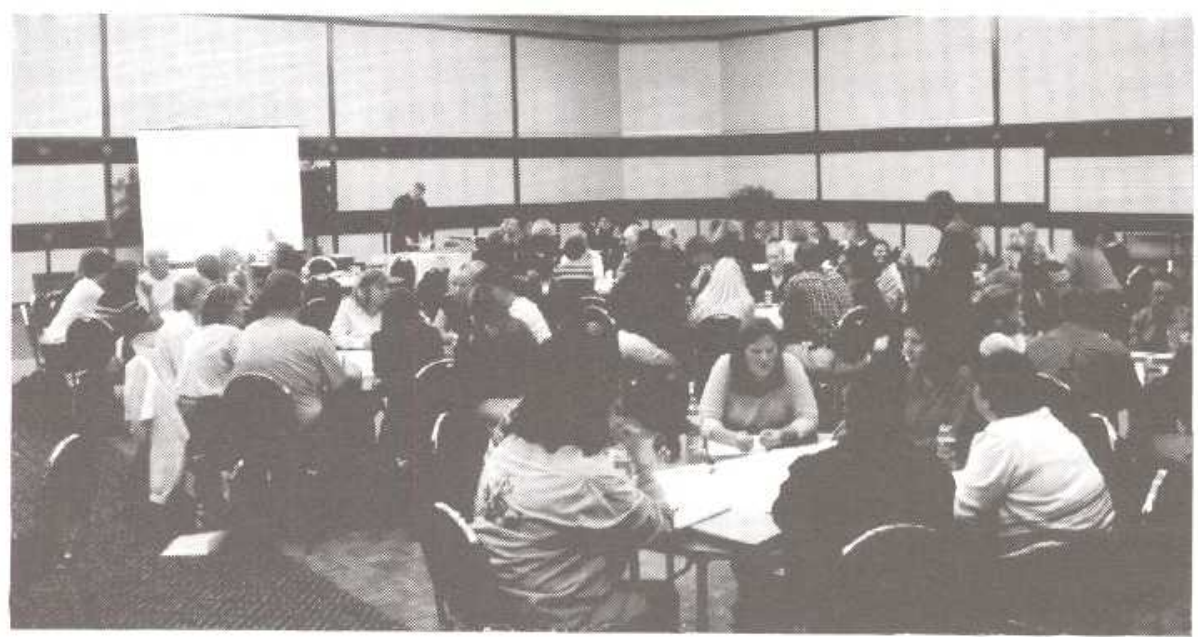

The chart on p. 12 identifies how various aspects of the assessment policy have been addressed the last few years.

The roles and responsibilities of staff played a part in determining what needed to be learned and who should be involved in the learning. It was essential that School Program Services coordinators and consultants provide consistent messages aligned with ministry policy and promote practices that were considered do-able. School administrators needed to have a common understanding of the new assessment practices to ensure that operational structures supported the practices. Each year a new group of teachers was added to the list of learners due to the staggered implementation of one grade per year over four years. This meant that there was and continues to be a diverse range of understanding across the system from one classroom teacher to the next. staff "buy-in" to why the changes needed to take place. System inservice packages were created to engage staffs in professional dialogue so that they could identify issues and concerns and begin to think about how the changes would benefit students. Staffs at the preparation stage were ready to move forward and wanted to know what changes needed to take place. In-school teams of teachers and school administrators were trained from each school to facilitate the learning with school staffs. The various aspects of the new assessment policy were introduced and related to changes in classroom practices. When staffs moved towards the practice stage, educators wanted to know how to implement the practices in their classroom. School Program Services coordinators and consultants provided subject specific support with program development teams ( 1 or 2 teachers from each school per subject/discipline) to ensure that the learning was relevant to the courses teachers were teaching. Some staffs are moving towards the routine stage. There is a realization that a different delivery model will be needed to move forward from where we are presently. Schools will need to develop a learning community approach so that teachers develop the level of knowledge and skills necessary to maintain and improve the quality of the teaching and learning.

Transforming our schools into results-oriented professional learning communities will build on the work we have done in the past and promote a high level of learning for all Halton students and educators in the future.

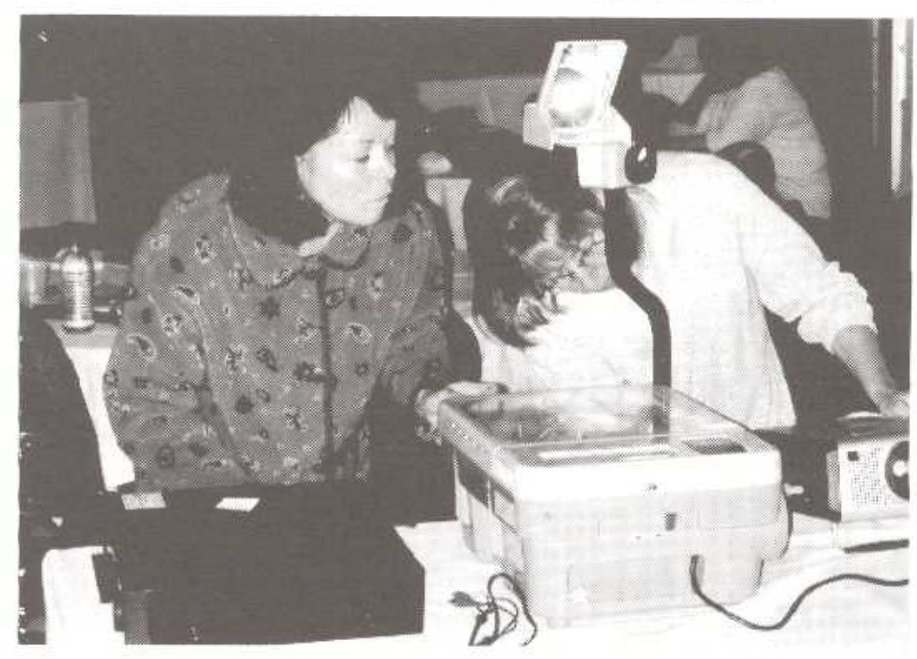

